IdeAs

Idées d'Amériques

$7 \mid 2016$

Cinéma et histoire dans les Amériques

\title{
Cinema e história nas Américas
}

Ignacio Del Valle Dávila e Eduardo Morettin

\section{(2) OpenEdition}

\section{Journals}

Edição electrónica

URL: https://journals.openedition.org/ideas/3144

DOI: 10.4000/ideas.3144

ISSN: 1950-5701

Este artigo é uma tradução de:

Cinéma et histoire dans les Amériques - URL : https://journals.openedition.org/ideas/1503 [

Outra(s) tradução(ões) deste artigo:

Cinema and History in the Americas - URL : https://journals.openedition.org/ideas/3103 [

Cine e historia en las Américas - URL : https://journals.openedition.org/ideas/3113 [es]

\section{Editora}

Institut des Amériques

\section{Refêrencia eletrónica}

Ignacio Del Valle Dávila e Eduardo Morettin, «Cinema e história nas Américas», IdeAs [Online], 7| 2016, posto online no dia 30 agosto 2018, consultado o 20 outubro 2022. URL: http:// journals.openedition.org/ideas/3144 ; DOI: https://doi.org/10.4000/ideas.3144

Este documento foi criado de forma automática no dia 20 outubro 2022.

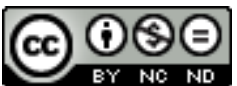

Creative Commons - Atribuição-NãoComercial-SemDerivações 4.0 Internacional - CC BY-NC-ND 4.0 https://creativecommons.org/licenses/by-nc-nd/4.0/ 


\title{
Cinema e história nas Américas
}

\author{
Ignacio Del Valle Dávila e Eduardo Morettin
}

1 O cinema é uma das principais expressões artísticas e culturais dos séculos XX e XXI. Ele também é um meio de comunicação de massa poderoso. Suas características fazem dele uma fonte primária de um grande interesse, tanto para o estudo dos projetos políticos quanto para aqueles dos imaginários coletivos de certas comunidades e em períodos históricos determinados. Por esta razão, inúmeros pesquisadores se interessaram pela relação entre cinema e história.

2 O dossiê "Cinema e história nas Américas" visa a compreender o papel exercido pelo cinema na representação do passado histórico de diferentes países do continente americano. Ao mesmo tempo, através deeste estudo, nós apresentamos diversas proposições práticas sobre a maneira de utilizar o cinema como uma fonte de estudo da história. Por consequência, os artigos propõem análises que abordam tanto os primórdios do cinema quanto suas tendências recentes: o cinema mudo, a passagem da linguagem visual a audiovisual, o desenvolvimento do melodrama e do filme histórico, o filme de autores dos anos 1960, o cinema militante dos anos 1960 e 1970 e os documentários autobiográficos dos últimos vinte anos.

3 Não é possível, em algumas páginas, recapitular de maneira exaustiva as principais contribuições teóricas que abrangem o cinema numa perspectiva histórica. Nós nos limitaremos a destacar alguns pontos de inflexão no desenvolvimento desse campo de pesquisa. De modo geral, podemos dizer que tanto os documentários como os filmes de ficção levaram décadas para encontrar a sua legitimidade como uma fonte para a história, apesar de uma grande força de penetração - especialmente para a ficção como entretenimento de massa, associado com a sua dupla condição de arte e de indústria. É somente a partir da obra de Marc Ferro, em 1970, publicado como livro em 1977, em Cinéma et histoire, que são sistematizados os princípios metodológicos do uso do cinema como uma fonte para o historiador. Segundo ele, a análise de imagens em movimento lançaria uma "contra-análise da sociedade", apontando para zonas de realidade latentes, "áreas não visíveis do passado das sociedades; revelando, por exemplo, as auto-censuras e os lapsos de uma sociedade" (Ferro M., 009: 27). Embora esta teoria tenha sido amplamente discutida e criticada nos últimos trinta anos, a 
defesa que ele fez do valor da imagem em movimento, como um "documento histórico" e "agente da história" em uma sociedade que produz e consome, permanece relevante para a pesquisa das relações entre cinema e história (Ferro M. 2009 17).

4 Este campo de estudos enriqueceu-se rapidamente com a publicação dos livros de Pierre Sorlin: Sociologie du cinéma, (Sorlin P., 1977) e The Film in History. Restaging the Past (Sorlin P., 1980). Sorlin, particularmente atento à relação entre o cinema de ficção histórica e a disciplina histórica, procurou demonstrar que a representação do passado no cinema deixa entrever questões políticas contemporâneas. Por outro lado, como o próprio Sorlin o reconheceu, seu interesse na década de 1980 pela semiótica, como método de abordagem de análise cinematográfica, parece menos relevante hoje.

Durante a última década do século XX e nesse início do século XXI, os estudos que associam o cinema e a história têm se expandido e diversificado. Além de uma revisão metodológica, tem havido muitos trabalhos que abordaram a análise de um filme ou de um contexto específico, e que ajudaram a verificar a validade destes princípios gerais. No contexto francês, Michele Lagny questionou o desenvolvimento de uma metodologia que, sem abandonar a análise do texto fílmico, considera indispensável para a sua interpretação a inserção no contexto cultural e na tradição cinematográfica, além da determinação das condições políticas e econômicas de produção (Lagny M., 2009). Em uma perspectiva diferente, a partir da observação da proliferação de "filmes de fantasia", Peter Beylot e Raphaelle Moine estavam interessados desde os anos 1980 na relação entre os filmes de ficção histórica e a noção de patrimônio histórico e cultural (Beylot P. e R. Moine, 2009). Sylvie Lindeperg, por sua vez, desenvolveu o conceito de microhistória em movimento para abordar Nuit et brouillard (Alain Resnais, 1955). Seu trabalho sobre este documentário mobiliza tanto a análise das formas cinematográficas quanto o estudo minucioso do contexto em que foi produzido e divulgado (Lindeperg S., 2007: 8). Quanto a Antoine De Baecque, ele está desenvolvendo o conceito de "história-câmera", através do qual procura demonstrar que o cinema pode ser considerado como uma forma de história por causa de sua capacidade de representar o passado, para se transformar em arquivo do passado e criar, através da montagem, novas formas de pensar sobre o passado reconstruído ou preservado em filme (De Baecque A., 2008 : 13).

No exterior, as obras de Robert Rosenstone tiveram um forte impacto. Segundo ele, os filmes históricos, incluindo a ficção, moldam a nossa consciência histórica, juntamente com outros meios de comunicação audiovisuais. O principal objetivo de Rosenstone é de investigar em profundidade como os filmes criam um mundo histórico (Rosenstone R., 2010). Em sua tentativa de compreender a construção do conhecimento sobre o passado através do cinema, o autor trata de colocar no mesmo nível o trabalho do cineasta e do historiador, embora as regras de interação de suas obras com o passado sejam diferentes (Rosenstone R., 2010 : 22). A tese de Rosenstone é que tanto a história como o cinema são relatos construídos por convençõesn e nos quais é possível encontrar elementos imaginários ou irreais. Desta forma, o autor insere tanto a produção acadêmica como as artes de palco em uma categoria difusa constituída por narrativas.

Devemos também observar uma renovação no campo da história do cinema. A partir do Congresso de Brighton, realizado sob os auspícios da Federação Internacional de Arquivos de Filmes, em 1978, a proximidade das questões levantandas pela história cultural permitiu elaborar a proposta de um método de análise de filmes que inclui a dimensão histórica. Nas palavras de Tom Gunning, um dos participantes: 
Se os métodos de análises dos filmes como sistemas de significado são diferentes dos filmes como uma mercadoria, eles não são mutuamente exclusivos e não são independentes em última instância. [...] Precisamos desenvolver métodos para analisar os próprios filmes que incluem uma dimensão histórica [...]; é hora de realizar uma comparação diacrônica dos filmes no centro da história (Gunning T., 1990: 86).

Rosenstone, Ferro e Sorlin são os principais autores com os quais a pesquisa latinoamericana consegue dialogar. Isso pode ser explicado, até certo ponto, pela tradução de seus livros em português e espanhol. Esse campo de pesquisa começou a crescer, em especial no Brasil, onde, desde meados da década de 1990, prolifera uma literatura científica $^{1}$. Pode-se mencionar os livros História e cinema (Capelato M. H., Morettin, E., Napolitano M. et al., 2007) ; Cinematógrafo: um olhar sobre a história (Nóvoa J., Biscouto Fressato S. e Feigelson K., 2009) ; História e Audiovisual, número espcial da revsta Estudos Históricos (Kornis M., 2012) ; o livro História e documentário (Morettin E., Napolitano M. e Kornis M., 2012) ; o dossiê As imagens no tempo e os tempos da imagem da revista Histórica, Questões \& Debates (Bastos Kern M. L. e Kaminski R., 2014). Pode-se também mencionar várias monografias como Canibalismo dos fracos (Freire A. Ramos, 2002), que se debruça sobre o filme Os Inconfidentes (Joaquim Pedro de Andrade, 1972), ou como Humberto Mauro, Cinema, História (Morettin E., 2013), bem como inúmeros artigos, jornadas de estudos, congresso, seminários e projetos de pesquisa.

9 Qualquer filme está em diálogo com a sociedade e com o tempo em que ele foi realizado. Ele incorpora e envolve imaginários e ideologias de uma sociedade em conflito, tendo ao mesmo tempo, potecialmente, uma capacidade de influênciá-los, como um agente histórico. Vamos prestar muita atenção à forma como os filmes estudados contribuem para a construção de imaginários sociais e à defesa de discursos e de projetos políticos. A fim de abordar o cinema como fonte para a história, deveremos ter em conta a sua especificidade artística e as características específicas da linguagem audiovisual. Se não o fizermos, poderíamos analisá-lo a partir de uma metodologia herdada da escrita, que se revela insuficiente para explicar o cinema como um documento de seu tempo. 0 desafio é justamente reconhecer a natureza específica do campo cinematográfico. Portanto, deve-se enfatizar a importância da análise do filme como uma ferramenta que permite não somente estudar o material cinematográfico como também estabelecer problemáticas que orientarão a reflexão.

10 Os artigos do dossiê observam três áreas geográficas - a América do Sul, o Caribe e a América do Norte - e quatro áreas de linguagem - hispanófona, lusófona, anglófona e francófona. Decidimos privilegiar o estudo nacional de caso para evitar o risco de uma visão geral, sem grande profundidade. No entanto, no caso das experiências cinematográficas concretas relacionadas com o exílio e migração, considerou-se que não é necessário seguir estas referências nacionais para oferecer uma fusão transnacional, porque o próprio objeto o exige.

11 O dossiê começa pelo Brasil, com os artigos de Ismail Xavier, Eduardo Morettin e Fernando Seliprandy. O primeiro explora a relação entre a alegoria histórica e o engajamento nos filmes do cineasta Glauber Rocha (ativo 1959-1980). Quanto a Eduardo Morettin, ele analisa as conexões entre a narrativa histórica e o discurso cinematográfico na representação da chegada dos colonizadores feita por Mauro num momento em que o governo de Getúlio Vargas (1930-1945) estava à procura de uma legitimação simbólica. Finalmente, Fernando Seliprandy examina as semelhanças e diferenças entre dois documentários que tratam do guerrilheiro Carlos Marighella: 
Marighella : retrato falado do guerrilheiro (Silvio Tendler, 2001) e Marighella (Isa Grinspum Ferraz, 2012).

Os filmes de ficção dos anos 1970 e 1980 são o objeto de dois artigos sobre o cinema argentino. Na primeira, Ignacio Del Valle Dávila analisa a relação entre o cinema histórico e o projeto ideológico da ditadura chamada "Revolução Argentina (1966-1973), a partir do filme El santo de la espada (Leopoldo Torre Nilsson, 1970), sobre a independência do heroi José de San Martín (1778-1850). Ana Laura Lusnich, por seu lado, estuda a preeminência de alegorias e metáforas nos filmes produzidos durante a última ditadura argentina (1976-1983) e no início do período pós-ditadura (1983-1989), como um reflexo do terror estatal e do controle social que caracteriza este período. A análise de Lusnich concentra-se nas longas-metragens Los miedos (Alejandro Doria, 1980) e Hay unos tipos abajo (Rafael Filipelli, Emilio Alfaro, 1985).

Mariana Villaça estuda a relação entre a política cultural do governo cubano e o influente Instituto Cubano del Arte e Industria Cinematrográfica (ICAIC), mostrando também os conflitos internos entre a gestão do instituto e alguns críticos cineastas em dois momentos particularmente tensos no campo cultural da ilha: 1968 e o início dos anos 1970. Os filmes Coffea Arábiga (Nicolás Guillén Landrián, 1968) e El otro Francisco (Sergio Giral, 1973) são objetos privilegiados para analisar estas relações.

Artigos de Anne-Marie Paquet-Deyris, Sergio Alpendre e Vincent Souladié se focalizam em diferentes épocas do cinema norte-americano. Anne-Marie Paquet-Deyris estuda a representação cinematográfica do presidente Abraham Lincoln, a partir de três filmes produzidos entre o início e o final de 1930: Abraham Lincoln (D. W. Griffith, 1930), Vers sa destinée (Young Mr. Lincoln, John Ford, 1939) e Abraham Lincoln (Abe Lincoln in Illinois, John Cromwell, 1940). Os outros artigos sobre o cinema hollywoodiano estudam as releituras daquilo que chamamos o sonho american, durante os momentos de crise. No primeiro deles, Sérgio Alpendre analisa os filmes de Rocky (John G. Avildsen, 1976) e La fièvre du samedi soir (John Badham, 1977) que ele considerada como metáforas de um momento de crise capitalista frente ao primeiro choque do petróleo. No segundo dessses artigos, Vincent Souladié faz uma análise crítica das relações, no que diz respeito às imagens, entre os filmes de super-heróis produzidos depois do 11 de setembro de 2001 e os ataques contra as Torres Gêmeas de Nova York.

O estudo da relação entre o cinema e a história na América do Norte fecha-se com uma análise de um filme inserido na área de língua francesa. Em seu artigo, Henri Gervaiseau analisa Le règne du jour (Pierre Perrault, 1967), explorando de que maneira os deslocamentos entre áreas sociais e geográficas remotas acabam formando um sentimento de pertença territorial. $\mathrm{O}$ dossiê temático é concluido por um artigo que dá em enfoque sobre experiências cinematográficas relacionadas com a migração e com o exílio político, insistindo na circulação e nos intercâmbios transnacionais. Jennifer Cazenave põe de manifesto a experiência da migração e do exílio a partir do estudo de dois "filmes-revistas": Reminiscences of a Journey to Lithuania (Jonas Mekas, 1973) e Diary (David Perlov, 1973-1983).

16 Todo o dossiê tem uma visão variada e complexa das relações entre cinema e história do continente, a partir de casos específicos que incluem uma boa análise tanto de contextos nacionais quanto de circulações transnacionais. Nós gostaríamos de salientar que a perspectiva histórica que orienta esses estudos promove a confluência produtiva entre pesquisadores de cinema de diferentes origens. A presença, neste dossiê, de 
textos escritos por especialistas em história, por estudiosos de cinema, por especialistas em comunicação e estética, marca esta orientação.

O leitor facilmente observará que as abordagens e temas de muitos textos interagem uns com os outros. Ismail Xavier e Ana Laura Lusnich enfatizam a importância da alegoria para o cinema; as narrativas de fundação são aspectos privilegiados por Eduardo Morettin, Ignacio Del Valle Dávila e Anne-Marie Paquet-Deyris; o ensaio de filme consituem o cerno dos estudos de Jennifer Cazenave e Henri Gervaiseau; o retrato hagiográfico é estudado por Anne-Marie Paquet-Deyris, Ignacio Del Valle e Fernando Dávila Seliprandy; a relação entre cinema e projeto revolucionário é observada por Ismail Xavier e Mariana Villaça.

Apesar da multiplicidade de questões evocadas, todos os artigos são caracterizados pelo papel central atribuído à análise de filmes para a compreensão de fenômenos históricos, nos quais se inscrevem as obras estudadas. Nós não julgamos pertinente reduzir essa multiplicidade de propostas a um número limitado de temas. No entanto, seria possível propor algumas tendências gerais. Todas as contribuições expõem diretamente a relação entre arte e política, em momentos diferentes e em formatos distintos. Neste sentido, é interessante notar que os trabalhos sobre a América Latina focam na ascensão e na crise do cinema político em iniciativas radicais, bem como sobre as relações mais ou menos tensas entre a produção de filmes e os governos autoritários. Em relação aos artigos sobre os EUA, o foco é, diferentemente, na relação entre, por um lado, o desenvolvimento do mercado de filmes, que torna possível produções de filmes cada vez mais espetaculares desde o início do século XX, e, por outro, o desenvolvimento ou a revisão de histórias melodramáticas centrradas no esforço e nas ambições de herois individuais. Essas histórias estão relacionadas com um imaginário que remete à concorrência, à luta pelo progresso social e pelo sucesso, o que constitui uma característica fundamental da sociedade norte-americana.

19 A origem deste número remonta aos últimos meses de 2013, quando uma primeira proposta foi apresentada à revista IdeAs. Esta é uma iniciativa do grupo de pesquisa "História e Audiovisual: circularidades e Formas de Comunicação" (História e Audiovisual: circularidades e formas de comunicação), coordenado por Eduardo Marcos Napolitano Morettin e professores da Universidade de São Paulo. Desde o início, a escolha foi feita para integrar cientistas de outras áreas acadêmicas, a fim de promover um diálogo internacional. Além da fixação institucional, a origem nacional dos autores é particularmente variada (brasileira, francesa, argentina, franco-brasileira, francoamericana, hispano-chilena), o que pode ser interpretado como um sinal de internacionalização crescente da pesquisa ${ }^{2}$. Por fim, a pluralidade dos enfoques deste dossiê evidencia a consolidação do campo de estudos centrados na reflexão entre o cinema e as ciências humanas. 


\section{NOTAS}

1. A lista desses trabalhos está disponível no site do grupo de pesquisa "História e Audiovisual: circularidades e formas de comunicação": http://historiaeaudiovisual.weebly.com/teses-edissertaccedilotildees.html, página consultada no dia 26 de março de 2016.

2. Enfatizamos, nesse sentido, a trajetória do professor Ismail Xavier - cujo artigo abre o dossiê uma das principais referências internacionais sobre a obra de Glauber Rocha e o estudo da alegoria no cinema latino-americano, cujos trabalhos têm sido amplamente traduzidos na Europa, nos EUA e na América Latina. As contribuições de Xavier fizeram com que ele fosse destacado no Dictionnaire de la pensée du cinéma (De Baecque A. et Chevalier P., 2012).

\section{AUTORES}

\section{IGNACIO DEL VALLE DÁVILA}

D’origine espagnole et chilienne, Ignacio Del Valle Dávila est docteur en cinéma (Université de Toulouse - Jean Jaurès), et a réalisé un post-doctorat en histoire à l'Université de São Paulo. Il est actuellement professeur de troisième cycle de l'Institut d'Art de l'Université de Campinas (Unicamp), où il poursuit ses recherches sur le cinéma latino-américain avec une bourse de postdoctorat CAPES. Auteur des livres Cámaras en trance: el nuevo cine latinoamericano, un proyecto cinematográfico subcontinental (Santiago du Chili, Cuarto Propio, 2014) et Le Nouveau Cinéma Latino-américain (1960-1974) (Rennes, PUR, 2015). Il est membre du groupe de recherche CNPq « História e Audiovisual: circularidades e formas de comunicação » et du conseil de rédaction de la revue Cinémas d'Amérique latine.

\section{EDUARDO MORETTIN}

Eduardo Morettin est professeur d'Histoire de l'Audiovisuel de l'École de Communications et des Arts de l'Université de São Paulo. Il est l'auteur de « Humberto Mauro, Cinema, História » et l'un des organisateurs de « História e Cinema: dimensões históricas do audiovisual » (2ème éd., SP, Alameda Editorial, 2011), « História e Documentário » (RJ, FGV, 2012) et « Visualidades Hoje » (Salvador, Edufba, 2013). Membre du Conseil de la Cinémathèque Brésilienne depuis 2007, il est l'un des responsables du groupe de recherche « História e Audiovisual: circularidades e formas de comunicação » (site http://historiaeaudiovisual.weebly.com/). Il est chercheur CNPq (Prix de productivité niveau 2), ayant réalisé un post-doctorat à l'Université Paris I (2012) 